\title{
Electrodeposited FePt Films
}

\author{
Fernando M. F. Rhen, G. Hinds, C. O'Reilly, and J. M. D. Coey, Member, IEEE
}

\begin{abstract}
A novel bath for electrodepositing FePt films was developed and films were electrodeposited on copper substrates with thickness up to $0.45 \mu \mathrm{m}$. The magnetic and structural properties of the films were measured. The films developed 0.3-T coercivity after annealing at $400^{\circ} \mathrm{C}$ and formed the $L 1_{0} \mathrm{FePt}$ phase. Films are shiny and smooth. Morphology was found to be affected by the annealing process.
\end{abstract}

Index Terms-Electrodeposition, films, $\mathrm{L}_{0}$ FePt, magnetization.

\section{INTRODUCTION}

$\mathbf{T}$ HE face-centered tetragonal FePt phase, known as the $L 1_{0}$ phase, is of interest for permanent magnet applications due to its excellent intrinsic magnetic properties $\left(\mu_{0} M_{s}=1.43 \mathrm{~T}, K_{1}=6.6 \mathrm{MJ} / \mathrm{m}^{3}\right)$ and corrosion resistance [1]. Numerous studies have been carried out to develop hard magnet films of this material due to potential application in high-density recording media and microelectromechanical (MEMS) systems [2]. Most of these studies have used sputtering, vapor deposition, or laser ablation. Thin-film samples typically show coercivities between 1-2 T [3]-[8] while bulk samples typically show coercivity values of $0.5 \mathrm{~T}$ [9]. Only recently, Huang et al. have electrodeposited nanowires of FePt in a porous anodized aluminum disk from a single bath [10] in despite of the remarkable progress on electrodeposited CoPt films [11]-[13]. Here, we present the first report in the literature of the preparation of continuous FePt films by electrodeposition from a novel bath and we also present their structural and magnetic characterization.

\section{EXPERIMENTAL DETAILS}

FePt films were electrodeposited on polycrystalline $\mathrm{Cu}$ substrates from a single bath containing $1 \mathrm{mmol} / 1 \mathrm{H}_{2} \mathrm{PtCl}_{6}$, $0.1 \mathrm{~mol} / 1 \mathrm{Na}_{2} \mathrm{SO}_{4}$ and $0.1 \mathrm{~mol} / 1 \mathrm{FeSO}_{4}$. The solution $\mathrm{pH}$ was adjusted to 2.9 by adding a small amount of either sulfuric acid or hydrochloric acid. The counter electrode was a 6-mm diameter by $50-\mathrm{mm}$ long graphite rod and the reference electrode was $\mathrm{Ag}-\mathrm{AgCl}$ saturated with $\mathrm{KCl}$ with factory calibration of $205 \pm 5 \mathrm{mV}$. All potentials are quoted with respect to this reference electrode. Solutions were prepared from $100 \mathrm{ml}$ deionized water. $\mathrm{Cu}$ substrates were used as working electrodes and cut out from $99.9 \%$ pure copper foil $0.5 \mathrm{~mm}$ thick into $5 \times 5 \mathrm{~mm}$ squares. These substrates were coated on one

Manuscript received December 23, 2002. This work is part of the framework of the European project for the development of high-temperature magnets "HITEMAG" which is supported by the Commission of the European Union (D.G. XII).

The authors are with the Physics Department, Trinity College, Dublin D2, U.K. (e-mail: rhenf@tcd.ie).

Digital Object Identifier 10.1109/TMAG.2003.815566 side with varnish and connected to a 1-mm copper wire. Just before electrodeposition, the substrates were dipped into a $10 \%$ $\mathrm{H}_{2} \mathrm{SO}_{4}$ solution to remove any oxide layers and then dipped into deionized water. Fresh solutions were vigorously stirred in open atmosphere at room temperature and the deposition took place immediately after inserting the substrate into the bath. The deposition was controlled using an EG\&G model 263A potentiostat.

Composition of the samples was determined by energy dispersive X-ray spectroscopy (EDX) and morphology was examined using a scanning electron microscopy (SEM). The crystalline structure was investigated by X-ray diffraction (XRD) with $\mathrm{Cu} K_{\alpha}$ radiation and a $0.02^{\circ}$ step. Magnetic properties were measured in a 5-T superconducting quantum interference device (SQUID) magnetometer and the thickness was evaluated in an atomic force microscopy (AFM) in the contact mode.

Films were deposited with thickness of about $0.45 \mu \mathrm{m}$. As-deposited films were amorphous and therefore subjected to annealing at temperatures between 400 and $700{ }^{\circ} \mathrm{C}$ under vacuum of $10^{-6}$ torr. The annealing process consists of heating up a furnace to the desired temperature, inserting the sample into the furnace at a temperature for the annealing time, then removing the sample and leaving it to cool down to room temperature, all under vacuum.

\section{RESUlTS AND DISCUSSION}

Platinum is electrodeposited from a complex ion $\mathrm{PtCl}_{6}^{-2}$ in two consecutive steps on the working electrode

$$
\begin{aligned}
& \mathrm{PtCl}_{6}^{-2}+2 \mathrm{e} \leftrightarrow \mathrm{PtCl}_{4}^{-2}+2 \mathrm{Cl}^{-} \\
& \mathrm{PtCl}_{4}^{-2}+2 \mathrm{e} \leftrightarrow \mathrm{Pt}+4 \mathrm{Cl}^{-} .
\end{aligned}
$$

The standard reduction potentials for the reactions (1) and (2) are 0.52 and $0.54 \mathrm{~V}$ quoted relative to $\mathrm{Ag}-\mathrm{AgCl}$ reference electrode [14]. As Pt is more noble than copper, we observed that the deposition of Pt takes place even without applying a potential to the electrochemical cell. The standard potential for $\mathrm{Fe}^{+2}$ reduction is $-0.669 \mathrm{~V}$. In this case, we have selected the concentration of $\mathrm{Fe}^{+2}\left(0.1 \mathrm{~mol} / 1 \mathrm{FeSO}_{4}\right)$ in order to have $\mathrm{Fe}$ deposition governed mainly by reaction kinetics and the concentration of $\mathrm{PtCl}_{6}^{-2}\left(1 \mathrm{mmol} / \mathrm{H} \mathrm{H}_{2} \mathrm{PtCl}_{6}^{-2}\right)$ in order to have Pt deposition in the mass transport regime. By measuring the thickness of the film in an AFM and taking account of the integrated charge, we estimated the current efficiency. Values of about $5 \%$ at $-0.7 \mathrm{~V}$ and $23 \%$ at $-1.1 \mathrm{~V}$ were found.

Pt content in the films was found to vary almost linearly around $-0.9 \mathrm{~V}$ as shown in Fig. 1. Films were shiny and homogeneous. EDX analysis showed distinct and very low intensity $\mathrm{Cl}$ peaks $\left(<1\right.$ at.\%) which comes from $\mathrm{PtCl}_{6}^{-2}$ complex ion. After the reduction of this complex ion the concentration 


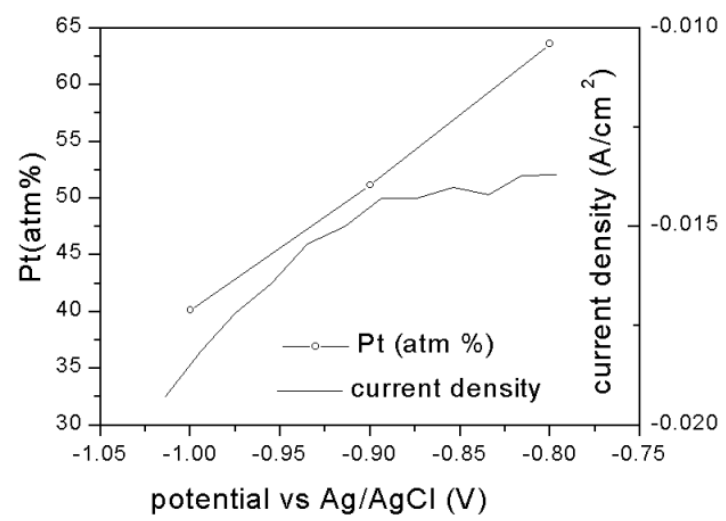

Fig. 1. Pt content as a function of the overpotential and current density applied to the electrochemistry cell.

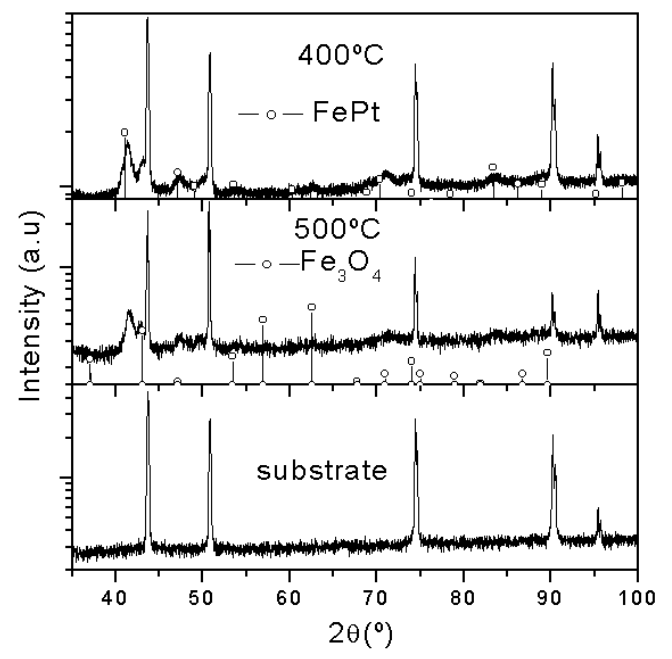

Fig. 2. XRD of FePt films annealed at $400^{\circ} \mathrm{C}, 500{ }^{\circ} \mathrm{C}$, and $\mathrm{Cu}$ substrate. Films electrodeposited at $-0.9 \mathrm{~V}$.

of $\mathrm{Cl}^{-}$increases on the surface of the working electrode; therefore, some of these ions are likely to be trapped by the depositing material.

Films electrodeposited at $-0.9 \mathrm{~V}$ with a total charge of $2.4 \mathrm{C}$ showed a thickness value of $0.45 \mu \mathrm{m}$ when plated over an area of $0.25 \mathrm{~cm}^{2}$. This gives a rate of $0.75 \mu \mathrm{m} \mathrm{C}^{-1} \mathrm{~cm}^{-2}$ that was verified between 0.6 to $2.4 \mathrm{C}$.

The diffraction pattern of as-deposited films at $-0.9 \mathrm{~V}$ showed only a broad amorphous hump. Films subjected to annealing developed a combination of ordered $L 1_{0}$ FePt phase and a minor amount of $\mathrm{Fe}_{3} \mathrm{O}_{4}$ as shown in Fig. 2. The optimized annealing time that leads to greater amounts of $L 1_{0} \mathrm{FePt}$ in the annealed samples at $400{ }^{\circ} \mathrm{C}$ is $20 \mathrm{~min}$, and at $500{ }^{\circ} \mathrm{C}$ it is $10 \mathrm{~min}$. Samples subjected to long annealing $(60 \mathrm{~min}$.) showed severe cracking that partially or totally peeled the film off the substrate. Fig. 3 shows the initial development of cracking in samples annealed at $400{ }^{\circ} \mathrm{C}$ for $20 \mathrm{~min}$. It is likely that these cracks are due to internal stress in the films which may come from gases absorbed during the deposition such as $\mathrm{H}_{2}$ and $\mathrm{O}_{2}$.

Magnetic measurements are shown in Fig. 4. The samples annealed at $500{ }^{\circ} \mathrm{C}$ exhibit coercivity of $0.2 \mathrm{~T}$ and the shape

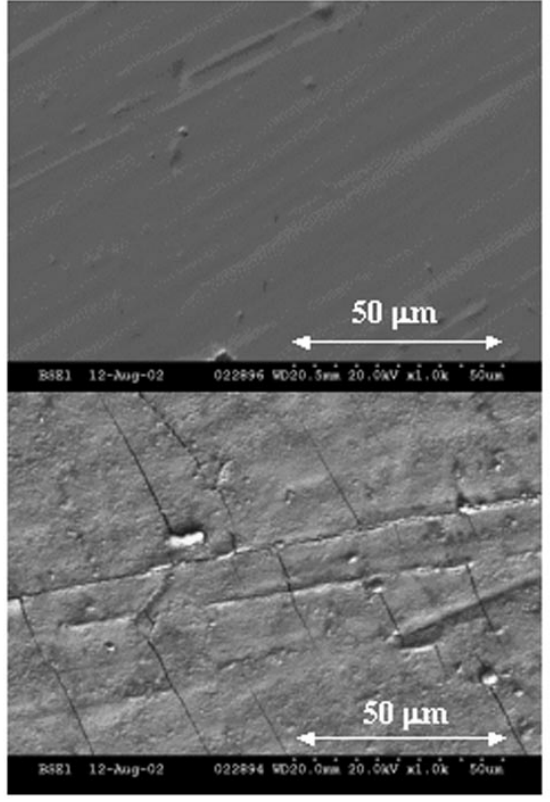

a)

b)

Fig. 3. SEM of sample (a) before and (b) after annealing at $400^{\circ} \mathrm{C}$ for $20 \mathrm{~min}$.

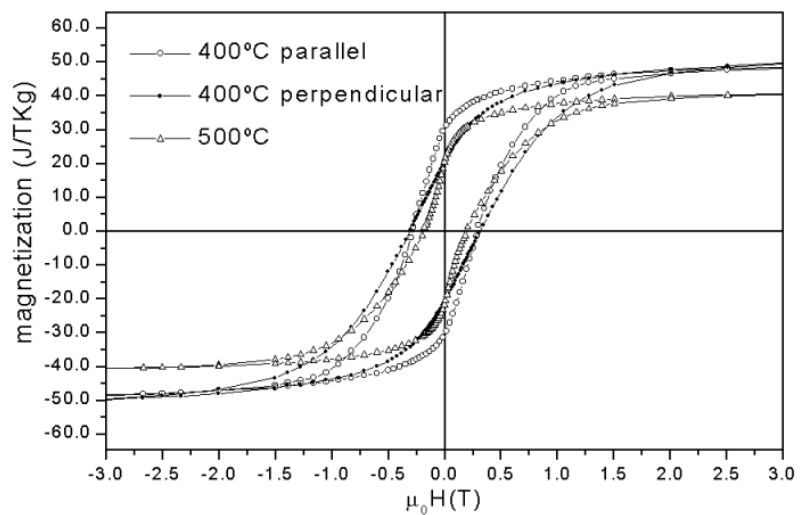

Fig. 4. Room temperature hysteresis loops of FePt films annealed $400{ }^{\circ} \mathrm{C}$ and $500{ }^{\circ} \mathrm{C}$.

of the magnetization curve suggests the presence of two-coupled phases where the major presence of the lower coercivity phase tends to reduce the coercivity when compared to samples annealed at $400{ }^{\circ} \mathrm{C}$ which show a higher coercivity $(0.3 \mathrm{~T})$ and better loop shape. Coercivity values in the present study are smaller than reported for FePt thin films (1-2 T) [3]-[8] and close to both values of FePt bulk (0.5 T) [9] and electrodeposited CoPt thin films (0.5 T) [11]. Saturation magnetization $50 \mathrm{~J} / \mathrm{Tkg}\left(\mu_{0} M_{s}=0.95 \mathrm{~T}\right)$ is in agreement with reported values for bulk samples produced by cold deformation [15]. The remanence ratio $\sigma_{\mathrm{r}} / \sigma_{\mathrm{s}}$ calculated for this sample is 0.65 , suggesting the existence of intergrain exchange interaction among the fine grains. The samples are magnetically isotropic.

\section{CONCLUSION}

We have presented the first report of continuous electrodeposited FePt film. The $L 1_{0}$ FePt phase was developed after annealing at $400{ }^{\circ} \mathrm{C}$, resulting in $0.3-\mathrm{T}$ coercivity. This 
method using a novel bath, when compared to vapor deposition methods, opens an alternative route for the production of FePt films that may be useful for MEMS applications.

\section{REFERENCES}

[1] R. Skomski and J. M. D. Coey, Permanent Magnetism. Bristol, U.K.: Inst. Physics, 1999, ch. 5.

[2] J. W. Judy and R. S. Muller, "Magnetically actuated, addressable microstructures," IEEE J. Microelectron. Syst., vol. 6, pp. 249-256, June 1997.

[3] J. A. Aboaf, T. R. McGuire, S. R. Herd, and E. Klokholm, "Magnetic, transport and structural properties of iron-platinum thin films," IEEE Trans. Magn., vol. 20, pp. 1642-1644, 1984.

[4] K. R. Coffey, M. A. Parker, and J. K. Howard, "High anisotropy L1(0) thin films for longitudinal recording," IEEE Trans. Magn., vol. 31, pp. 2737-2739, Nov. 1995.

[5] R. A. Ristau, K. Barmak, L. H. Lewis, K. R. Coffey, and J. K. Howard, "On the relationship of high coercivity and L1(0) ordered phase in CoPt and FePt thin films," J. Appl. Phys., vol. 86, pp. 4527-4533, 1999.

[6] A. Cebollada, D. Weller, J. Sticht, G. R. Harp, R. F. C. Farrow, R. F Marks, R. Savoy, and J. C. Scott, "Enhanced magneto-optical Kerr effect in spontaneously order FePt alloys: Quantitative agreement between theory and experiment," Phys. Rev. B, vol. 50, pp. 3419-3422, 1994
[7] B. M. Lairson, M. R. Visokay, R. Sinclair, and B. M. Clemens, "Epitaxial PtFe (001) thin films on $\mathrm{MgO}(001)$ with perpendicular magnetic anisotropy," Appl. Phys. Lett., vol. 62, pp. 639-641, 1993.

[8] J. P. Liu, C. P. Luo, Y. Liu, and D. J. Sellmyer., "High energy products in rapidly annealed nanoscale Fe/Pt multilayers," Appl. Phys. Lett., vol. 72, pp. 483-485, 1998.

[9] K. Watanabe and H. Masumoto, "On the high energy product of Fe-Pt permanent magnet alloys," J. Jpn. Inst. Met., vol. 47, pp. 699-703, 1983

[10] Y. H. Huang, H. Okumura, G. C. Hadjipanayis, and D. Weller, "CoPt and FePt nanowires by electrodeposition," J. Appl. Phys., vol. 91, pp. 6869-6871, 2002.

[11] G. Zangari, P. Bucher, N. Lecis, P. L. Cavallotti, L. Collegaro, and E. Puppin, "Magnetic properties of electroplated Co-Pt films," J. Magn. Magn. Mater, vol. 158, pp. 256-257, 1996.

[12] V. Georgescu, V. Mazur, and O. Cheloglu, "Preparation and magnetic properties of electrodeposited Co/Pt multilayers," J. Magn. Magn. Mater, vol. 156, pp. 27-28, 1996.

[13] P. L. Cavallotti, N. Lecis, H. Fauser, and A. Zielonka, "Electrodeposition of magnetic multilayers," Surf. Coat. Technol., vol. 105, pp. 232-239, 1998.

[14] Handbook of Chemistry and Physics, 53rd ed., R. C. Weast, Ed., Chemical Rubber Co., Cleveland, OH, 1972, p. D-112.

[15] N. H. Hai, N. M. Dempsey, M. Veron, M. Verdier, and D. Givord, "An original route for preparation of hard FePt," J. Magn. Magn. Mater, vol. 257, pp. L139-L145, 2003. 